\title{
Managing the Interdependencies in Complex Development Projects with Matrix-Based Methods
}

\author{
Vinod Ramachandran \\ School of Science, Aalto University, Espoo, Finland
}

\begin{abstract}
The design structure matrix or the dependency structure matrix is a modeling framework used in many areas of research and practice. It is suitable for illustrating the dependencies between product, organization, and the development processes in a complex development project. "The products" considered in this paper are the unique product, service or result of the complex development projects; "the organizations" have a complex, interrelated networked organizational structure; and "the process" is the product development processes involved in a complex development project. The inter-organizational networks created in such development projects are temporary, and the critical parameters are cost, time, and product quality, as it is in other projects. The potential of Design structure matrices and domain mapping matrices to illustrate the dependencies between such complex product, process, and organization systems is analyzed. The review investigates the existing literature in the mainstream of project management discussing the design structure matrix and other related matrix-based methods.
\end{abstract}

Keywords: DSM, Project management, Project interdependencies, Complex development projects.

\section{Introduction}

The design structure matrix (also known as dependency structure matrix or dependency structure modeling) is a modeling framework used in many areas of research and practice. It considered as suitable for illustrating and managing the dependencies between product, organization, and the development processes in complex product development project (Danilovic and Browning, 2007). This study explores the appropriateness of Design structure matrix (DSM) and other matrix-based methods for analyzing the complex interdependencies in a development project. The products considered here are the development projects of complex product systems (CoPS), with complex, interrelated networked organizational structure and multifaceted product development processes involved in a complex development project. CoPS are high cost, engineering-intensive products, systems, networks, and constructs with high levels of uncertainty (Hobday, 1998). The potential of the Design structure matrix, Domain mapping matrix (DMM), and Multi-domain matrix (MDM) to illustrate the dependencies between such complex product, process, and organization systems have to be investigated. The interorganizational networks created in such development projects are temporary, and the significant factors are cost, time, and quality as it is in other projects. This study is more 


\section{Part III: Project Management}

focused on the project management aspects of such projects, but the product development aspects also considered.

The central phenomenon studied is the interdependence between the three different but important aspects in a product development project such as product, organization and process and their interdependencies. The design structure matrix and the other related modeling frameworks such as multi-domain mapping matrix and the domain mapping matrix are supposed to be valuable in illustrating the relationships among the three significant aspects in a development project. The development project is considered as a system composed of different subsystems, and there are various components in each subsystem (Nightingale, 2000). The three different subsystems in a development project system are product subsystem, process subsystem, and the organization subsystem. The modeling of the interrelation between these three subsystems using the multi-domain matrix and mapping of the relation between the individual components in a subsystem using the design structure matrix are the areas which should be further developed. Each subsystem could be considered as a domain, and the relationship between the three domains mapped using the multidomain mapping matrix, and the relationship between any of the two domains mapped using the domain mapping matrix. The advantages of using such a modeling framework are its simplicity and brevity in representation; less complication in analyzing the dependencies between different subsystems; and the ability to highlight the essential patterns in system architecture (Browning, 2016).

Design structure matrix (DSM) to represent the task dependencies in product design has come into the limelight with the works of Steward (1981a; 1981b). The use of DSM framework in project management has been established, but it is spreading gradually into the realm. The study of interdependencies between different subsystems in complex development project subsystems provides numerous opportunities for future research in the field of project management. Overall the use of the dependency structure modeling or the design structure matrix offers a new avenue in the analysis of complex product systems and their development projects. The complexities in the projects, products, processes, and the organizations are increasing, and the management of such intricacies and uncertainties are of utmost importance in the management of complex development projects. The diagonal cells in a design structure matrix or the dependency and structure modeling can represent the components of subsystems in a complex development project, such as components of product subsystem, organization subsystem, or the development process subsystem. The off-diagonal cells can represent the interdependencies or the interactions between the components in a product, process, or the organization subsystem. The components that can be modeled are the different modules of a product, people in an organization, or the activities in a process (Browning, 2016).

There is an interdependence between the product architecture and the organizational structure since the communication pattern and the technological traditions of an organization affect the product architecture. An established organization has typical communication patterns, and it is difficult to adapt to the novel product architecture of a complex product system. The study conducted by Sosa et al. (2004), shows misalignment of product architecture and organizational structure in complex product development and offer insights about interdependencies across organizational and functional boundaries. The other two out of the five elements of the project are the project goals and the project tools. The interdependence between the project goals architecture and the project tools 


\section{Ramachandran}

architecture can also be modeled using the dependency and structure modeling. There are static and temporal DSM to model the different architecture such as product architecture, organization architecture, process architecture, project tools architecture, and the project goals architecture. This paper mainly considers the product, organization and process architectures and their interdependencies, and the modeling framework using the design structure matrix (DSM), domain mapping matrix (DMM) and the multi-domain matrix (MDM).

The N-square chart for modeling and managing the product component interfaces can be combined with the design structure matrix in the systems engineering. In the product architecture, DSMs are used to model relationships among components and modules, and the relationship between different functions in the product subsystem. The products divided into components and modules can be represented with a product breakdown structure, and the design structure matrix can illustrate the relationship among those components and modules. Modularity is another attribute of the complex system which is based on minimizing the interdependence between modules and maximizing the dependence within them. There should be a framework to integrate and analyze the relationship between product, production system and organizational design modularity (Campagnolo and Camuffo, 2010), and the design structure matrix could shed some light on this aspect. It is essential to increase the inter-rater reliability of the design structure matrix to take advantage of it for analyzing the modularity of product, production system, and the organizational design.

Nightingale (2000) studied the relationship between product, process, and organization in complex development projects, and provides a framework linking products to the innovation process, based on the empirical case study of the design of aero-engine. The study explores the relationship between technology, knowledge, and organization, but matrix-based methods to investigate the interdependence between the product architecture, the innovation process, and the organization is not evident in the study. The study by Artto and Turkulainen (2018) found interesting interdependencies between product and organization subsystems of a 'major project' when analyzed at the component level. They used an analysis framework built on the volume-variety matrix, by using the form of a multidomain matrix (MDM), and the relationship between the organization and the product subsystem components are presented using the domain mapping matrix (DMM) (Artto and Turkulainen, 2018).

The product innovation is a key variable that differentiates a firm from its competitors, and the design organizations contribute to a firm's core competence. There are different networks of actors in the design organizations of a complex system. The sustainable competitiveness of a firm can be enhanced by linking the competence-based and valuecreating network management and the use of matrix-based tools to manage the interdependencies between product, process and the organization domains of design projects (Bonjour and Micaelli, 2009). DSM can represent the architecture of a design core competence, and evaluate it concerning the product, process, and organizational architectures. Systems engineering framework and standards are valuable to organize the intricate design in complex product development projects. The final product in the large complex development projects is the integration of all the components, modules or subsystems, and the system integration team responsible for integrating the complex system. The representation of relationships between various components is helpful for system 
Part III: Project Management

architects and design managers. Bonjour and Micaelli (2009) proposed a conceptual framework that represents the links between key concepts involved in the building of design core competence. The suggested core competency criteria tree in the study has evaluated the core competence.

Another challenge in the complex product systems is the redesign of the system, change propagation, and the prediction and management of change. There are several change propagation paths may be possible in a complex product. The knowledge of change propagation paths and its impact on the product is significant in the redesign and change management of a complex product system. Sosa et al. (2007) studied the effect of the aspect of modularity on the redesign at the component level of a complex product system. The change prediction would also be useful in project planning and the subsequent redesign. Clarkson et al. (2004) studied different mathematical models to predict the risk of change propagation in terms of likelihood and impact of change. The higher degree of change propagation is likely in a highly complex product system. A well-organized functional structure of a product with minimized information content can reduce complexity and the propagation of change (Clarkson et al., 2004). The redundancy usually designed into complex products to afford a degree of change, but significant changes can affect the schedule and cost in design projects. DSM can support to foresee the change propagation through a product, however further development of the method is required to make it suitable for highly complex product systems. It is important to understand the links that exist between different parts of the product and its impact on change propagation.

The project complexity consists of technological complexity and organizational complexity, and the interdependencies are the most significant drivers of project complexity (Baccarini, 1996; Vidal and Marle, 2008). The awareness of the interdependencies and the understanding of the consequences of complexity in a development project are imperative. The uncertainties and change propagation are more complex to manage (Vidal and Marle, 2008). DSM can support mathematical models that could comprehend project interactions and assist in decision making when managing complex development projects.

\section{DSM in Project Management}

For this paper, the author analyzed the existing literature in the domain of project management that mentions the design structure matrix, or the dependency structure matrix, or the dependency and structure modeling. The purpose is to study the application of the matrix-based methods in the project management stream, to analyze the interdependence between product, process, and organization in a complex development project. The articles in the leading project management journal, International Journal of Project Management (IJPM), were analyzed and 22 journal articles in the IJPM that mentions design structure matrix (DSM), or the dependency structure matrix, in the project management context are identified. The query string TITLE-ABS-KEY ("design structure matrix" OR "dependency structure matrix" OR "dependency structure model*" OR "dependency and structure model*" OR "multidomain matrix" OR "domain mapping matrix") AND (LIMIT-TO (EXACTSRCTITLE, "International Journal of Project Management")) in the Scopus reference database returned 7 results. The citation analysis and further refining provided a 


\section{Ramachandran}

total of 22 journal articles that mentioned DSM. There are 1,354 document results returned without the "source title" limit. Most of the Design Structure Matrix related publications are in the Journal of Engineering Design, IEEE Transactions on Engineering Management, and Systems Engineering. A relatively small number of articles in the domain suggests that the design structure matrix applications have to strive to penetrate deep into the mainstream of project management. Indeed, further effort is needed to advance the adoption of DSM for the interdependence analysis of complex development projects.

The design structure matrix (DSM) has demonstrated its effectiveness as a tool for representing and analyzing the individual system, such as a product, process, or organization architecture (Danilovic and Browning, 2007). The complex product development projects have intricacies because of the interactions between product, development process, organizational structure, tools, technologies, and project goals. Tools are required not just to analyze the components in an individual project subsystem, but also to compare two or multiple project domains. Danilovic and Browning (2007) formalized an approach to compare two different project domains using a domain mapping matrix (DMM). This complements traditional DSM analysis and provides a better avenue to investigate the interdependencies in a complex development project. Yang et al. (2015) describe quantitative models based on Multi-Domain Matrix (MDM) and Design Structure Matrix (DSM) in their paper, to manage communication and coordination complexity in the global product development (GPD) project. Chen et al. (2003) observed the shortcomings in the traditional project scheduling tools in the areas, such as sequencing, monitoring and controlling in the large global-collaborated New Product Development (NPD) projects, and presented a project scheduling and rescheduling framework based on DSM. Earlier, in the project management realm, DSM has been used as a tool to enable critical path calculations.

While planning and scheduling projects, the estimation of natural overlap project duration is important, Maheswari and Varghese (2005) discussed this issue and proposed a detailed implementation procedure to estimate it using DSM. Shi and Blomquist (2012), proposed an approach for managing project schedules, using fuzzy set theory, within uncertain conditions of information dependency. Generally, project managers make use of traditional project management tools and techniques to address uncertainty and resource allocation in a complex development project in a multi-project environment. The use of the dependency structure matrix and domain mapping matrix approach enables the systematic identification of interdependencies and relations in development projects in a multi-project environment (Danilovic and Sandkull, 2005). The management of uncertainty with the information exchange using DSM and DMM provides better visualization and creates accountability for the complex development project in a multi-project environment. Yang et al. (2014) made use of DSM to highlight the process architecture in the product development projects to describe the dependency relationships between activities.

The literature review also identified studies related to the application of DSM in software development projects. A probabilistic model is developed by Fu et al. (2012), based on the design structure matrix (DSM) to evaluate the risk of change propagation from requirements to the software architecture. The DSM based approach for process restructuring that model information flow across tasks based on large-scale system decomposition cited by Ghosh and Varghese (2004). 


\section{Part III: Project Management}

In the course of examining the effect of utilizing initial information on the redesign, total design duration, and the overall project duration, Chua and Hossain (2011) used DSM to present dependency between various design activities. DMM and DSM methods provide cross-project visibility and support for management decisions in complex product development environments, nonetheless network mapping and analysis tools have the potential to enhance the understanding of multi-level project interdependencies, according to one study (Killen and Kjaer, 2012). Browning (2014), included the design structure matrix in the different project management models and views present in the concept of a process architecture framework (PAF) to manage the complexity in large complex projects. Further, studies also mentioned design structure matrix tools along with managing interdependencies in development projects (Killen, 2013; Abrantes and Figueiredo, 2015), project methodology (Padalkar and Gopinath, 2016), project complexity (Qazi et al., 2016; Vidal et al., 2011), identification of links in the project risk network (Yang et al., 2016), and depiction of dynamism in development processes (Abrantes and Figueiredo, 2015). Some of them also stressed the benefit of visual representation of interdependencies in complex projects and project networks using tools like network mapping. To deal with the complexity and non-linearity of the design process, Austin et al. (2002) developed analytical design planning technique (ADePT) methodology which integrated dependency structure matrix (DSM) analysis along with the process modeling and the production of design programs. It provides a more systematic way of approaching the interdependencies between tasks of complex design projects.

The following are the summary of the findings from the literature review:

- The design structure matrix applications should get more consideration in the field of project management.

- Further studies needed to advance the adoption of DSM for the interdependence analysis related to all the technological and organizational aspects of the complex development projects.

- Matrix-based methods are already in place to represent and analyze the interdependencies within the individual domains and to compare and analyze the interdependencies across multiple domains in a project.

- Shortcomings in the traditional project scheduling methods could be overcome with the help of project scheduling framework and methodologies based on DSM.

- Matrix-based methods provide better visualization of various interdependencies and hence assist in the management of uncertainty.

\section{Conclusions}

The matrix-based methods like Design Structure Matrix (DSM), Domain Mapping Matrix (DMM), and Multi-Domain Matrix (MDM), have high prospects in the realm of project management. The modeling and analysis of complex interdependence between the elements such as product architecture, development processes, and organizational structure 


\section{Ramachandran}

in a complex development project facilitate the management of those complexities and related uncertainties. Further studies are required regarding the interdependence between product, process, and organization in the development of complex product systems (CoPS), and matrix-based methodologies should be further upgraded to map and efficiently analyze such complex interdependencies. An architecture framework and management information system should be developed by integrating process, product, and organization architectures, which provides an overall view of the interdependencies in a complex development project. In general, the evaluation of interdependence pattern in complex development projects using the tools based on the principles of graph theory combined with the network analysis tools opens up several novel streams of research in the project management domain.

\section{References}

Abrantes, R., and Figueiredo, J. (2014). Feature based process framework to manage scope in dynamic NPD portfolios. International Journal of Project Management, 32(5), 874-884.

Abrantes, R., and Figueiredo, J. (2015). Resource management process framework for dynamic NPD portfolios. International Journal of Project Management, 33(6), 1274-1288.

Artto, K., \& Turkulainen, V. (2018). It takes two to tango: Product-organization interdependence in managing major projects. International Journal of Operations \& Production Management, 38(6), 1312-1339.

Austin, S., Newton, A., Steele, J., and Waskett, P. (2002). Modelling and managing project complexity. International Journal of project management, 20(3), 191-198.

Baccarini, D. (1996). The concept of project complexity - a review. International journal of project management, 14(4), 201-204.

Browning, T. R. (2014). Managing complex project process models with a process architecture framework. International Journal of Project Management, 32(2), 229-241.

Bonjour, E., \& Micaelli, J. P. (2009). Design core competence diagnosis: a case from the automotive industry. IEEE Transactions on Engineering Management, 57(2), 323-337.

Browning, T. R. (2015). Design structure matrix extensions and innovations: a survey and new opportunities. IEEE Transactions on engineering management, 63(1), 27-52.

Campagnolo, D., and Camuffo, A. (2010). The concept of modularity in management studies: a literature review. International Journal of Management Reviews, 12(3), 259-283.

Chen, C. H., Ling, S. F., and Chen, W. (2003). Project scheduling for collaborative product development using DSM. International Journal of Project Management, 21(4), 291-299.

Chua, D. K. H., and Hossain, M. A. (2011). A simulation model to study the impact of early information on design duration and redesign. International journal of project management, 29(3), 246-257.

Clarkson, P. J., Simons, C., \& Eckert, C. (2004). Predicting change propagation in complex design. Journal of Mechanical Design, 126(5), 788-797.

Danilovic, M., and Browning, T. R. (2007). Managing complex product development projects with design structure matrices and domain mapping matrices. International journal of project management, 25(3), 300-314.

Danilovic, M., and Sandkull, B. (2005). The use of dependence structure matrix and domain mapping matrix in managing uncertainty in multiple project situations. International journal of project management, 23(3), 193-203.

Fu, Y., Li, M., and Chen, F. (2012). Impact propagation and risk assessment of requirement changes for software development projects based on design structure matrix. International Journal of Project Management, 30(3), 363-373. 


\section{Part III: Project Management}

Ghosh, P. P., \& Varghese, J. C. (2004). Globally distributed product development using a new project management framework. International Journal of Project Management, 22(8), 669-678.

Hobday, M. (1998). Product complexity, innovation and industrial organisation. Research policy, 26(6), 689-710.

Hossain, M. A., and Chua, D. K. H. (2014). Overlapping design and construction activities and an optimization approach to minimize rework. International journal of project management, 32(6), 983-994.

Killen, C. P., and Kjaer, C. (2012). Understanding project interdependencies: The role of visual representation, culture and process. International Journal of Project Management, 30(5), 554-566.

Killen, C. P. (2013). Evaluation of project interdependency visualizations through decision scenario experimentation. International Journal of Project Management, 31(6), 804-816.

Maheswari, J. U., and Varghese, K. (2005). Project scheduling using dependency structure matrix. International Journal of Project Management, 23(3), 223-230.

Nightingale, P. (2000). The product-process-organisation relationship in complex development projects. Research policy, 29(7-8), 913-930.

Padalkar, M., and Gopinath, S. (2016). Six decades of project management research: Thematic trends and future opportunities. International Journal of Project Management, 34(7), 1305-1321.

Qazi, A., Quigley, J., Dickson, A., and Kirytopoulos, K. (2016). Project Complexity and Risk Management (ProCRiM): Towards modelling project complexity driven risk paths in construction projects. International Journal of Project Management, 34(7), 1183-1198.

Shi, Q., and Blomquist, T. (2012). A new approach for project scheduling using fuzzy dependency structure matrix. International Journal of Project Management, 30(4), 503-510.

Sosa, M. E., Eppinger, S. D., and Rowles, C. M. (2004). The misalignment of product architecture and organizational structure in complex product development. Management science, 50(12), 1674-1689.

Sosa, M. E., Eppinger, S. D., \& Rowles, C. M. (2007). A network approach to define modularity of components in complex products. Journal of mechanical design, 129(11), 1118-1129.

Steward, D.V. (1981a). The design structure system: A method for managing the design of complex systems. IEEE transactions on Engineering Management, (3), 71-74.

Steward, D.V. (1981b). System Analysis and Management: Structure, Strategy and Design. Petrocelli Book, McGraw Hill, New York.

Vidal, L. A., and Marle, F. (2008). Understanding project complexity: implications on project management. Kybernetes, 37(8), 1094-1110.

Vidal, L. A., Marle, F., and Bocquet, J. C. (2011). Measuring project complexity using the Analytic Hierarchy Process. International Journal of Project Management, 29(6), 718-727.

Yang, Q., Kherbachi, S., Hong, Y. S., and Shan, C. (2015). Identifying and managing coordination complexity in global product development project. International Journal of Project Management, 33(7), 1464-1475.

Yang, Q., Lu, T., Yao, T., and Zhang, B. (2014). The impact of uncertainty and ambiguity related to iteration and overlapping on schedule of product development projects. International Journal of Project Management, 32(5), 827-837.

Yang, R. J., Zou, P. X., and Wang, J. (2016). Modelling stakeholder-associated risk networks in green building projects. International journal of project management, 34(1), 66-81.

Contact: Vinod Ramachandran, Aalto University, Department of Industrial Engineering and Management, Maarintie 8, 02150 Espoo, P.O. Box 15500, 00076 AALTO, Espoo, Finland, Phone: +35850513 4940, E-mail: vinod.ramachandran@aalto.fi 